\title{
Why is an Application of Multiple Intelligences Theory Important for Language Learning and Teaching Speaking Ability?
}

\author{
Malai Boonma \\ Graduate School, Nakhon Ratchasima Rajabhat University \\ 340 Suranarai Rd., Muang District, Nakhon Ratchasima Thailand 30000 \\ E-mail: malai_de_dee@yahoo.co.th \\ Malinee Phaiboonnugulkij \\ Faculty of Humanities and Social Sciences, Nakhon Ratchasima Rajabhat University \\ 340 Suranarai Rd., Muang District, Nakhon Ratchasima Thailand 30000 \\ E-mail: malineerabit@hotmail.com
}

Doi:10.7575/aiac.alls.v.5n.5p.162

Received: $18 / 07 / 2014$

URL: http://dx.doi.org/10.7575/aiac.alls.v.5n.5p.162

Accepted: 05/08/2014

\begin{abstract}
This article calls for a strong need to propose the theoretical framework of the Multiple Intelligences theory (MI) and provide a suitable answer of the doubt in part of foreign language teaching. The article addresses the application of MI theory following various sources from Howard Gardner and the authors who revised this theory for using in the field of the English speaking improvement domain. In other word, this article combines and summarizes appropriate elements for the person on how to start teaching with this theory. The article also describes sequences and implication of the theory into practice. MI theory with the description of eight intelligences characteristic is presented. Following is the parts of activities catering and the processes of teaching with MI are provided. This article ends with the reviews of the ways for assessment and examples of lesson plan integrated with MI theory.
\end{abstract}

Keywords: Multiple Intelligences, Speaking ability, Teaching Speaking

\section{Introduction}

Almost educators in field of language teaching and learning today have stuck in the ways giving method for raising their learners' success. It is very difficult to define the activity of the lesson suitably the learners needs in learning class time as well. Therefore, they may be need time for depth study on the learners learning style that something involve in this progress. The number of research has offered various strategies or theory to lead them all, one is the Gardner's theory. This theory is called "Multiple Intelligences" that the theoretical framework is defined in all different learning profile areas. The theory address on the difference of the intelligence a person is, that within a person there are at least eight intelligences from their birth although it express in strength and weakness domain. This theory is given the people being aware of their own ways to develop and respect within the personal profile that can be improved in any ways by practicing or doing. The theory is also good for the educators be aware of giving the material in teaching and learning that value for the learners to be gained the achievement effectively in domain. Garner $(1983,1999)$ claims that the people can improve their learning through at least eight views: Linguistic, Logic-Mathematical, Visual-Spatial, BodyKinesthetic, Music-Rhythmic, Intrapersonal, Interpersonal, and Naturalist. Accordingly, foreign language teachers can promote their learners by focusing into one or more of the intelligence that the learners will use most. In Gardner's list, it showed the importance of varied human intelligences, and all of the engagement of intelligences. Moreover, types of children obtaining knowledge enable teacher to use many activities to serve children with different kind of intelligence. The multiple intelligences theory guided a variety of teaching strategies which can be applied in the language classroom. Most importantly, this theory helps teacher to select effective teaching strategies that cater for their predominant (Campbell. 2008: 187). However, the problem of it is how many educators really understand the definition of Multiple Intelligences theory enough to bring the function of it into the lesson for teaching and learning. Especially, in term of language teaching and learning that involve the interpretation one's language to other language this seems they have to do something in double ways at same time. The theory is expected to be used with a number of learners' difference leaning profile they are, thus, there is a strong need to understand the theory's function in deeply. The present article therefore aims to provide a theoretical framework of Multiple Intelligences that defined by Howard Gardner and the function of the Multiple Intelligences theory within the framework of foreign language teaching and learning. The activity and lesson are concluded for reasonable consideration to account the ways they can prepare for. 


\section{The Feature of Multiple Intelligences Theory}

In the past intelligence is accounted as the IQ test that could be objectively measured to a single number score. As presented in 1904 by the French psychologist name Alfred Binet and a number of colleagues to develop on purpose to receive primary grade students' attention in learning for avoiding failure. Next, intelligence is used in USA to evaluate the capacity of the learner finding the score of the intellect in academic areas. The IQ test is used when there is a need to identify that a child has some disability in learning. Over the years after that, the first intelligence tests were developed against the belief of the Harvard psychologist name Howard Gardner. According to Gardner our culture had defined intelligence too narrowly. However, IQ test are valid for predicting academic achievement, but unable to use assess success in determining the ways of intelligence a person is (Gardner.1999). Gardner (1983) proposed a new theory to define the intelligence as his eyes intelligence is "the capacity to solve problems or to fashion products that are valued in one or more cultural settings, to create effective product thereby laying the groundwork for the acquisition of a new knowledge" (Gardner, 1993:15). He also defined intelligence as "a bio-psychological potential to process information that can be activated in a cultural setting to solve problems or create products that are value in culture" (Gardner. 1999 : 34). He stated that all individuals have personal intelligence profiles that consist of conductions of seven exotic intelligence types. These intelligences are listed as: Verbal - linguistic, Logical- mathematical, Visual-spatial, Bodilykinesthetic, Musical-rhythmic, Intrapersonal, and Interpersonal, later he added two intelligences that were Naturalist and Existentialist intelligence (Gardner 1983,1993, 1999). At this point Existential intelligence it is not very specifically defined, therefore there are eight intelligences that Gardner provided a means of mapping the broad range of abilities that human process their capacities into comprehensive categories, to make it clear Armstrong (2000:2), Armstrong (2009) and Palmberg (2011: 5) presented as the following:

1. Linguistic: The capacity to use language effectively that relates all four skills. In term of using language to convince, remember information, inform and talk about others to take a specific course of action. Types of the occupations that are involved this intelligence such as poets, journalists, editors, a storyteller, politician, and including the characteristic type of people who good acquire foreign language. Linguistic learners learn best through speaking, explaining, writing, listening, storytelling, reading, and analyzing language syntax in circumstance of topic they have learned.

2. Logical-mathematical: The capacity to use numbers effectively through logical patterns and relationships. People is illustrated this intelligence from who prefer thinking in complex pattern to find quality or enjoy finding pattern in shapes and numbers. The numbers of occupations involved who are strong in this area like mathematician, a tax accountant, statistician, a scientist, computer programmer, and logician. Logical- mathematical learners learn best through mathematical context or new information that is related into experiments by giving reason or asking for achieving new answer to offer their work.

3. Visual-Spatial: The ability to realize the visual world accurately and to perform transformations upon those perceptions. This intelligence involves the sensitivity to color, line, shape, form, space, and the relationships that exist between these elements. The characteristic of occupations such as a hunter, scouts, guides, an interior decorator, architects, artists, or invents, mechanics, graphics, architects, and engineers. Spatial intelligence learners learn best through all of new information is presented in form of diagrams, picture, mazes, and maps that they can visualize their idea.

4. Bodily-kinesthetic: The expertise in using one's whole body to express ideas, feelings and facility in using one's hands to produce or transform things. The occupations are involved in this area such as crafts-people, surgeons, mechanics, a mime, athletes, dancers, actors and all of whom good at playing on stage or good in fine motor skill related in making model or sculpture. Bodily-Kinesthetic learners learn best by using body to create some idea that involve on the topic they learn. Especially, learns through various kinds of movement.

5. Musical: The capacity to perceive, discriminate, transform, and express musical forms. This intelligence includes sensitivity to the rhythm, pitch, melody, and timbre or tone color of a musical piece. The occupations such as singers, musicians, composers, conductors and who all do well with note, enjoy making rhythmic sound or display involves musical in circumstance. Musical learners learn best through the new information is presented in the context of a chant or song. They prefer learning through verbal lectures, discussions, listening to tone of voice.

6. Interpersonal: The ability to perceive and make distinctions in the moods, intentions, motivations, and feelings of other people. This can include sensitivity to facial expressions, voice, and gestures. The occupation types such as psychologists, teachers, parents or who gives some consults and services. Interpersonal learners work well with pairs and groups and they learn best through discussing, sharing some new information with others. Thus, interpersonal learners like to interact with others and learn best in groups or a partner.

7. Intrapersonal: Self-knowledge and the ability to have an awareness of one's self emotional states while doing something. This intelligence includes the capacity for self-discipline, self-understanding, and self-esteem. Intrapersonal learners learn best by thinking through new information on one's self. Therefore, intrapersonal learners are reflective, analytical and intuitive about who they are and how and what they learn.

8. Naturalist: Expertise in the recognition and classification of the numerous species as the flora and fauna of an individual's environment. In addition, the abilities to allow people to be aware distinguish stem and study the circumstance environment of their live. The characteristics of people involve this intelligence such as florists, gardeners, framer, geologist, archaeologists, and people who prefer study about the natural environment. Naturalist 
learners learn best if new information is presented in a nature context, especially giving them compare and contrast the information that they have already learned.

According to the lists above, teachers need to understand the key point of MI theory as: (1) One person has all eight intelligences in all from their birth although difference is weak and strong in their both. (2) Everyone can develop all eight intelligences in many ways to high level if given suitably supportive. (3) All intelligences do not exist by itself that means all eight intelligences support one other intelligence in many ways of their contexts. (4) Each category of intelligence has no standard that one can be shown in diversity of the ways their gifts (Armstrong, 2009). Therefore, teachers have to be aware of their mind all of individuals possess certain combinations of the diversity intelligences in different contexts. Thus, it is important to master that learners intelligence ways to assess them all over time (Hatch, 1997).

\section{Function of multiple intelligences theory on English language teaching and learning}

According to Gardner's MI theory the application can apply to many areas of academic curriculum depend on the ways they purpose. The activity uses in English language teaching need to consider the difference of the aspect between other subjects. As Palmberg (2011) states that creative teachers have always had the enviable ability to look at a given language activity and immediately know how it could be used in the classroom. In other word, one should be very strict when interpreting the instructions of each activity. Christison (1996) adds ELT classroom activity has a complex different from other academic field that the effective teaching activity need to apply through the four steps such as: 1) Teachers have to identify the activities for serving to each particular type of intelligence profile that will be used in their learning classroom. 2) Teachers have to set plans by grouping appropriate classroom activities for supporting the students' needs like learning strategies or learning styles. 3) Teachers have to use MI checklist to keep track of different activities that used in the class. The purpose for developing all the eight multiple intelligences profile. 4) Teachers have to exam and analyze their checklists for neglecting intelligences a period of time they can do. The purpose for developing lesson plans that foster of learners really needs.

Therefore, understanding the areas of MI activities is more important to prepare lesson for teaching English subjects. For the purpose of teaching English as a foreign language, the activity is considered in order to cater for the different types of intelligences. These activities have presented in several sources to show how MI theory can be applied to practice in the EFL classroom effectively. These activities have been identified based on (Lazear, 1994; Campbells \& Dickinson, 1999; Armstrong, 2000- 2009 ) as bellows.

Linguistic Intelligence activities: making conversations to relate on topics of study, learning new words and grammatical points using them accurately in regular communication, reading a story to choose appropriate word to fill in a gap in a sentence, writing summary to keep track of thought and idea, listening a story to choose an appropriate synonym or antonym for answering different questions related to a text.

Logical Mathematical Intelligence activities: practice puzzles to find a hidden rationale or patter, sequencing events in a chronological order, finding logical errors, presenting timelines of events presented in a story or a text, mapping the idea that will happen next in certain topic, making systematic presentation of subject matter, inventing point by point logical explanations for items, creating meaningful connections between different ideas.

Bodily Kinesthetic Intelligence activities: creating a mini drama that shows the dynamic interplay of various topics of study, arranging and doing TPR and hands on activities, drawing and coloring the objects to show their idea, using part of body to solve the problem, and making models of objects relate to topic of study.

Visual Spatial Intelligence activities: using pictures, diagrams, and concept maps to facilitate learning and encouraging students to make the visual aids by themselves, matching pictures with appropriate words on topic of study, describing pictures or images to facilitate their thinking, finding connection between visual designs or patterns and encouraging students to express their view for all of learning topic.

Musical Intelligence activities: playing songs in order to introduce a topic or analyze the lyrics, transforming lyrics into a text or task on topic of study, creating songs for a class, producing sounds with one's vocal cords to illustrate the meaning of words, and employing musical instruments to produce sounds for a lesson as background accompaniment.

Interpersonal Intelligence activities: offering input on one's performance or about one's opinions, analyzing a character to discuss a topic problem with a partner or with others in teams, retelling a story distinct segments from each other on the process of putting it back to its original form, rewriting a text from another's character point of view, and accepting another's input or reaction to one's opinions.

Intrapersonal Intelligence activities: writing journal to keep their idea or activities in order to elicit personal experiences, sharing personal experiences to support topic of study, learning the ability to focus one's mind on a single idea or task, and creating something to support of self esteem learning.

Naturalistic Intelligence activities: working with classification matrices to understand characteristics of natural objects, comparing or representing nature in some, categorizing form of animal and plant to analyze the difference class, doing project relate nature context, performing experiments or activities that use objects from the natural world, and exposing the senses to nature's sounds, smells, tastes, touches, and sights. 


\section{Begin with Multiple intelligences}

Although Gardner's MI theory is proposed for many years, many foreign-language teachers are less really knows about this theory and the use, especially to apply into the foreign language classroom. According to Palmberg (2011) suggests that teachers have to really know how to study and apply of MI theory step by step in flied of teaching foreign language that using different from other subjects. Therefore, he offers the steps that teacher can start to access MI theory easily as below.

Step1: Teachers need to start with reading a book involve MI theory that many sources in present day are available on the topic as find from research articles, books and online.

Step 2: Teachers identify their personal MI profile by using MI checklist that for finding their predominant strength and weakness.

Step 3: Teachers need to identify their students' MI profiles the purpose to know their strongest intelligence through personal learning in the field of foreign language. The checklist is not the same that need to consider that suitably the level of students.

Step 4: Teachers start to categorize classroom activities according to intelligence types which one activity can cater several intelligences at the same time.

Step 5: Teachers try to combine language skills activities and intelligence types as for four skills speaking, writing, reading and listening. Note that one activity can interpret more single skill depends on teaching context.

Step 6: Teachers need to identify the MI profile of a foreign language textbook use in the class learning. Concluding the number of activities that the textbook contains and then decide for each activity which intelligence types it catered for.

Step 7: Teachers start to identify the MI profile of a foreign language lesson that can make a list of the main phases which intelligence types it catered for.

Step 8: Teachers prepare an MI-based lesson outline that can math all tasks, texts, exercises, visual aids, classroom activities. Note that all of ideas according to the intelligence type which will be most suitable for.

According to MI theory, the concept of teaching has no standard that mean multiple intelligences can apply through various materials and various activities with suitable the context. Therefore, teachers need to know the traditional basic ways to teach the multiple intelligences as well as the effective learning to be gained. Jasmine (1996) presents the ways to teach for preparing the benefit lesson as: (1) Infusion: is to take an area of the curriculum or an objective that involve each of intelligence for preparing lesson plan suitably to teach in the classroom. (2) Centers-Based curriculum: is based on theme that a center holds the instructional plans together are created to intelligences. (3) Project-Based: is used to full advantage that students are thought to develop their own project which an individual can show intelligence they are straight through the project they produce. (4) A separate subject: is a method of instruction in which you take one of the intelligences and demonstrate it in such a way that an environment will be provided to support a crystallizing experience.

From the ways teaching above, lesson plan is important to set the activities through a large number of different MI profiles, but teacher do not prepare individual lesson plans for every student in the class that mean foreign language exercises can cater for several intelligence types at the same time. Palmberg (2011:32) states that the ways to set lesson plan for teaching in classroom is the teachers have to support learning relax in environment exercise. The features in particular can promote students' self-esteem as: 1) Sharing the goals of the lesson with the students: knowledge of the teaching goals makes students realize that what they are going to learn that will hopefully motivate them to participate actively in the various phases of the lesson. 2) Exploiting and emphasizing the existence of the potential vocabulary in the foreign language: knowing the clue of foreign language word meaning give them to easily guessable into their mother tongue. 3) Providing students with "support frames" containing the vocabulary items and key phrases needed for communicative activities: showing some phrases to communicate help learner who slow acquire that manage fear.

\section{Assessment of Multiple Intelligences}

The importance of learning for success in field of the effectiveness is based on the method for assessment that gives the learners to check their achievement for finding the intellect they are. The assessor needs to set the problem that can be solved in material which the intelligence displays in context. Thus, assessment should be used in a part of general learning environment to find the process evidence. Gardner (1993) states that an important aspect of the individual's ability to solve problems or create products must drawn from different intelligences and determine toward which one an individual masters and how potentially he access it. Armstrong (2009) adds that the ways of the most important MI theory is presented through the educator to be aware of assessment the learning progress. Using authentic assessment as observation or documentation is really benefited to gain effectively in areas of the measurement different intelligence. Gardner (1993) the assessment of multiple intelligences widely, but assessment must base on the criteria as: 1) It should be intelligence fair. 2) It should be developmentally appropriate. 3) It should be linked to recommendations. Therefore, Gardner suggests the ways the multiple intelligences are assessed in many areas as: 1) Assessing by observation, for in stand, using a checklist that design to link to specific activities or level you want your learner to reach. This process will show progress over a period of time. 2) Assessing by checklist that need to analyze task or material to make meaningful checklist for achieving a particular goal. 3) Assessing by anecdotal records that account of what has happened. This process helps positive comments that document the development and growth of learners. 4) Assessing by portfolios that store all of works to compare in order to observe progress over a period of time. This process to show real evidence of 
learners progress to recognize their have done is good or not. 5) Assessing by reflections that assess from something learners to form a good or bad opinion about thing they produce to account the progress completely. 6) Assessing by rubrics that use to be a scoring guide based on something in progress of learning purpose. This process can be created by teacher and learners' acceptation to use for judgment about various possibilities in assessment. 7) Assessing by translation that assess from the progress of learner has changed some idea to another area to account their intelligence such as give kinesthetic learners act feeling from the scenes to explain their understand areas.

\section{Speaking Ability and Teaching Speaking}

Harmer (2007) states that many people learn English because they have moved into the target language community that mean they need to be able to operate successfully with community. For example, such students of general English often do not have a particular reason for going to English class, but simply wish to learn to speak the language effectively for wherever and whenever this might be useful for them. In other word, many people learn English speaking because they think it will be useful in some way for international communication and travel. It would to say speaking English is one of the ability so much a part of daily lift that we take it for granted. He also states who can learn more one language relate to using several intelligences abilities. Especially, learning speaks other language this ability seems as a basic skill more than other form of four skills. In other word, multiple intelligences is important for teaching language speaking ability because of human always first can communicate with other people by trying to speak this ability come before they learn on the lesson. In addition, Lightbown and Spada (2006:185) support of learners who have a wide diversity of intellectual abilities can be successful language learning. Especially, if they emphasis is on oral communication skill rather than metal-linguistic knowledge. It would to say that teaching speaking ability involve into function of MI at least eight intelligences is that learners simply use their different intelligences predominant from their birth more than other of four skills to acquisition language. According to, Harmer (2001 : 269) claims that speaking is considered like ability to process information and language that students need to access the element necessary for producing the speaking ability through as: (1) Connected speech: this help students understand how to modify sounds which omitted and added. (2) Expressive devices: this always helps students understand using the pith and stress to convey the meaning. (3) Lexis and grammar: this helps students understand using several of phrases in deferent context use. (4) Negotiation language: this helps students to think before decision to speak out that is gained effective speaking. To put it more simply, Kayi (2006) suggests that teaching speaking ability is to teach learners to produce the English speech sounds and sound patterns which are related using sentence stress as intonation patterns and the rhythm of the second language, selecting appropriate words and sentences according to the appropriate context, and using the language quickly, fluency and confidently. There are authors have offered the ways to help teacher in order to develop their teaching speaking class in flied of English speaking as a second language. As for the students success in study to speak and can communicate freely while student is practicing. As Bailey (2005: 30) suggests teacher will consider key issues in teaching speaking regardless of the levels. That mean teacher should know that these terms may use somewhat differently from one region to another, and even from on program to another. Difference of learners' level is usually showed as beginning, intermediate, and advanced. The principle is concerned as possible in teaching speaking which can influence in teaching areas. There are three levels of student as below.

1. Principles for teaching speaking to beginning students: provide something for learner to talk about, create opportunities for students to interact by using group work or pair work, and manipulate physical arrangement to promote speaking practice.

2. Principles for teaching speaking to intermediate students: plan speaking task that involve negotiation for meaning, design both transactional and interpersonal speaking activities, and personalize the speaking activities whenever possible.

3. Principles for teaching speaking to advanced students: help students to combine fluency and accuracy, encourage students to take reasonable risk in speaking English, and provide opportunities for students to notice the gap.

In addition, Bailey (2005: 124) states some useful suggestion for English language teachers while teaching oral language to be aware of their stress through particular teaching as: (1) Provides maximum opportunity to students to speak the target language by providing a rich environment that contains collaborative work, authentic materials and tasks, and shared knowledge. (2) Try to involve each student in every speaking activity; for this aim, practice different ways of student participation. (3) Reduces teacher speaking time in class while increasing student speaking time. Step back and observe students. (4) Indicate positive signs when commenting on a student's response. (5) Do not correct students' pronunciation mistakes very often while they are speaking. Correction should not distract student from his or her speech. (6) Involve speaking activities not only in class but also out of class; contact parents and other people who can help. (7) Circulate around classroom to ensure that students are on the right track and see whether they need your help while they work in groups or pairs. (8) Provide the vocabulary beforehand that students need in speaking activities. (9) Diagnose problems faced by students who have difficulty in expressing themselves in the target language and provide more opportunities to practice the spoken language. Accordingly, Brow (2007 : 326-327) supports another issue that is to consider how to make speaking easier while student is practicing, teacher can give some directions to solve this problem in many ways they progress. The lists of characteristics of spoken language can make speaking performance easy as well as in some case it difficult such as by clustering, redundancy, reduced forms, performance variables, colloquial language, stress, rhythm, and intonation. They always help students do not stick while they are speaking. Therefore, activities that teacher prepare have to consider to broaden students' abilities and perception, not against their natural prejudices or emphasis their limitation. (Harmer 2007:94) 


\section{Conclusions}

The various reasons of using Multiple Intelligences theory in flied of foreign language classroom learning are numerous. This always can separate the use of this theory into four parts of the people who to be gained the benefit in this areas.

First, benefit for the learners that help them to improve their abilities effectively. In other word the abilities are developed when they are running by the activities through concept of multiple intelligences theory. Moreover, this theory also serves various possibilities to involve learners know how to organize their assessment and it also gives them the opportunity to think about the ways they are learning.

Second, benefit for teachers and educators that it is important for them to be aware of the different types of the intellects which the learners are. In other word they need to support the learners and create an opportunity to develop their special abilities that different style in the ways they have, especially given them feel comfortable in the classroom to achieve a better outcome in variety distinctions.

Third, benefit for the parents that the theory helps them understand their children closely in the ways of the different profile. These will help them to support in many early ways as possible so that they can do for their children in field of providing thing for the difference intelligent types they have. It is really important for parents because they are the ones that relate very directly more that other people who can response to children at many times before they go to school.

Fourth, benefit for people who needs to develop their knowledge in field of the intellect they are, if they really know the ways they strength and weakness they can fill their gap for mastery at many time as possible. This function not only help them to be a regular person but also not except the people who are the lame person in society they response for.

According to MI theory the human's capacity is not static, in other word they can be developed and it depends on the purpose whom they are. Therefore, in the same ways people are given the opportunity to consider the different types of intelligence and it is important that they can response which one suits their strengths and their interests to be taken into account and motivating them effectively. This can be summarized that the function of Multiple Intelligences theory in the field of foreign language teaching and learning can be benefited and advanced by all of the people in this areas.

\section{References}

Armstrong, T. (2000). Multiple Intelligences in the classroom. ( $2^{\text {nd }}$ ed.). Alexandria, VA : Association for Supervision and Curriculum Development.

Armstrong, T. (2009). Multiple Intelligences in the classroom. ( $3^{\text {rd }}$ ed.). Alexandria, VA : Association for Supervision and Curriculum Development.

Bailey, K. M. (2005). Practical English language teaching. New York : Mc Graw-Hill ESL/ELT.

Brown, H. D. (2007). Teaching by principles : An interactive approach to language Pedagogy. ( $3^{\text {rd }}$ ed.). US : Pearson Longman.

Cambell, L. B., \& Dickinson, D. (1999). Teaching and learning trough multiple intelligences. (2 ${ }^{\text {nd }}$ ed.). Needham Heights : Allyn \& Bacon.

Christison, M.A. (1996). Multiple intelligences and second language learners. [Online] Available : http://www.njcu.edu/CILL/vol3/christison.html. (march13, 2013).

Gardner, H. (1983). Frames of mind. New York : Basic Book.

Gardner, H. (1999). Intelligences reframed: Multiple intelligences for the 21st century. Basic Books, Member of the Perseus Books Group.

Gardner, H. (1993). Multiple Intelligences: The Theory in Practice. New York: Basic Books

Harmer, J. (2001). The practice of English language teaching. China: Longman

Harmer, J. (2007). How to teach English. Malaysia : Pearson Longman.

Harmer, J. (2007). The practice of English language teaching. ( $4^{\text {th }}$ ed.). UK: Pearson Longman.

Hatch , T. (1997). Getting specific about multiple intelligences. [Online] Available : http:// www.ascd.org/reading room/edlead/9703/hatch.html. (March 10,2013).

Jasmine, J. (1996). Multiple intelligences activities grades 5-8. Teachers Created Materials, Inc. Huntington Beach.

Kayi, H. (2006). Teaching speaking: Activities to promote speaking in a second language. [Online] Available : http://iteslj.org/Tecniqes/Kayi-teachingSpeaking.html (October 20, 2012).

Lazear, D. (1994). Seven Pathways of learning: teaching students and parents about multiple intelligences. US : Zephyr Press.

Lightbown, P and Spada, N. (2006). How language are learned.( $3^{\text {rd }}$ ed.). Oxford University Press.

Palmberg, R. (2011). Multiple intelligences revisited. [Online] Available: www.esldepot.com/pdf/english clubmultiple intelligences- revisited.pdf (March 15, 2013).

Ur, P. (2006). A course in language teaching. Uk : Cambridge University Press. 


\section{Appendix}

\section{Lesson Plan}

Level: grade 9 students

Topic: Eating Out!

\section{Concept :}

Eating is a traditional of being life, to learn about how to talk in various situations involves food, ordering, requesting, offering, and suggestion the food is important to the students. It is beneficial for students practice to speak, and use it in daily life in many contexts as well.

Objectives :

Students are able to identify foods and use language about eating at restaurant context.

Procedures :

Phase 1. Ask students what the English sentences may have to use in the restaurants situation for they often use in talking as ordering, requesting, offering, and suggestion. Then shows students the V.D.O related in eating and using word, sentences to order, ask for and give offering. (Visual-spatial, verbal-linguistic, musical- intelligences and interintrapersonal intelligences)

Phase 2. Hands out a worksheet 1 with contain two columns of the sentences involve the conversation in restaurant context. One column lists English sentences and the second column lists sentences in Thai language. The students, worksheet 1 is to match the English words with Thai language equivalent. After a few of minutes, give the correct answers on an overhead transparency and then do quick choral dill on the pronunciation of these sentences.

(Logic-mathematical, verbal-linguistic, intrapersonal, and musical- intelligences)

Phase 3. Divides the students into a group of three students and tell them make the script for acting, each student gathering he/her sentences for speaking which involve the context these will be presented in worksheet 2 . Students can look at their book or ask for helping from their teacher to make the script. While they are working open music "I like to eat" for giving the atmosphere of working is relaxed.

(Interpersonal, intrapersonal, logic-mathematical, verbal-linguistic, and musical- intelligences)

Phase 4. Asks each group to act follow their script that the role of each students different from each other. The content of the script one students have to be a waiter and two students have to be customers. The conversations have to relate for ordering, requesting, offering, and suggestion.

(Bodily-kinesthetic, verbal-linguistic, intra-interpersonal, naturalist and visual-spatial) 